\title{
Moral Values Education in Terms of Graduate University Students' Perspectives: A Jordanian Sample
}

\author{
Amani Jarrar ${ }^{1}$ \\ ${ }^{1}$ Faculty of art and science, Petra University, Amman, Jordan \\ Correspondence: Amani Jarrar, Faculty of Art and Science, Petra University, P. O. Box 961343, Amman, Jordan. \\ Tel: 962-795-522-401. E-mail: aj_infinity@yahoo.com
}

\author{
Received: December 14, 2012 Accepted: January 6, 2013 Online Published: January 10, 2013 \\ doi:10.5539/ies.v6n2p136 URL: http://dx.doi.org/10.5539/ies.v6n2p136
}

\begin{abstract}
This study focuses on how moral values differ and vary according to variants such as education, culture, thoughts, religion, gender and family relations. It handles the issue of moral education in Jordan, from the perspective of graduate students in Petra University. Since we are facing new challenges in this era and region of the world, we are more affected by cultural and environmental effects that change our moral system. This ethical issue is highly important in a world where materialistic values are more pressing on our behavior. This study directly tackles Jordanian culture and mainly youth in universities, so that a specially tailored questionnaire was built to study the moral value educational system that Jordanian youth in private universities believe in, taking Petra University as a sample. This questionnaire covers all areas of morality and all issues dealing with ethical dilemmas, and their answers were analyzed according to certain dimensions that have to do with moral education, moral dilemmas, moral choice, moral crises, moral sensation, moral awareness, the awareness of right, and justice from the perspective of Jordanian graduate students. Many factors were being taken into consideration, especially the eastern, Muslim, Jordanian culture, the youth mentality affected by education, the Arab culture, information systems, and human rights issues. The study ends with a description of the moral value education system of graduates in Petra University as a special model of private universities.
\end{abstract}

Keywords: moral education, moral values, ethics, arab culture, moral behavior

\section{Introduction}

It seems we are facing a real problem in promoting morality in our higher education system, so if higher education must do something about moral values, it is not to promote standards disregarded everywhere outside the classroom, for example. So that in Dewey's terms, to replace customary morality by reflective morality, which is in a university moral education, what is essential is the acquisition and cultivation of materials and skills of moral reflection.

As Plato once said: Man is a tame animal, and good needs only to be known to be desired, this is why we should internalize moral norms through moral education.

So if morality imposes a duty to work for changes in society, the role of higher education is to contribute to change, not by direct action, but by the force of ideas, and the farthest it reaches the human spirit, is what makes higher education.

I believe that moral education is more effectively caught than taught. And that moral change is nowadays in a state of moral collapse.

According to Kantian morality, a person is a rational agent; being rational, a person recognizes the good and ought to act in accordance with the universal moral law of the categorical imperative, so that morality is a sense of duty. As Kant expressed his view of moral consciousness, that people should act always as if the maxims of their action were to become a universal law.

Thus higher education does have a role to play in stimulating the moral life of our communities. (Thompson, 1993)

Therefore, I assume that the most suitable perspective is to have an inter-disciplinary approach to moral education, and that is what I call to have a just community approach to moral education. 


\subsection{Study Importance \& Objectives}

This research paper focuses on one of the most important challenging factors in the world of moral education in Jordan, as one of the model countries in the Middle East, where graduate and under-graduate students make a big part of its people. This research tries to shed light on moral education in Jordan, its reality and perhaps ways to develop it.

\subsection{Problem \& Research Questions}

The research problem is a reflection of the moral values education in Jordan, and the state of moral values from the students' points of views.

This research tries to answer the following questions:

How is moral awareness affecting Jordanian university students' moral behavior?

Is there any kind of moral education affecting the students' thinking of morality and moral behavior?

What are the main factors affecting moral values in terms of youth perspectives?

\section{Literature Review}

\subsection{Previous Studies}

Leming, J., "Curricular Effectiveness in Moral/Values Education: A Review of Research", Journal of Moral Education, Vol. 10(3), 2006. The research was on the curriculum effectiveness of moral/values education approaches. Two approaches (values clarification and moral development) were identified as having sufficient completed research to warrant examination. A total of 59 studies were reviewed, 33 focusing on values clarification and 26 with moral development as the focus. The research on values clarification indicated that little or no confidence is warranted regarding its potential curricular effectiveness. On the other hand, the research base for the moral development approach indicated that cautious optimism is appropriate. Finally, suggestions were offered for future research on these two approaches.

Bebeau, M., Beyond the Promise: A Perspective on Research in Moral Education, Sage Journals, 1999. The research is about changing concerns and ideological shifts in American society producing different emphasis in moral education. He argues that different approaches address different dimensions of development. If viewed as complementary rather than contradictory, he may be able to move beyond ideological and philosophical disputes to solid theory-building based on empirical findings. In proposing an action program for moral education that incorporates research, he drew upon lessons learned from the Head Start movement. In defining researchable variables, he recommended the Four Component Model (sensitivity, judgment, motivation, character) instead of the usual tripartite model (thinking, feeling, and acting).

J O'Toole, Leading Change: The Argument for Values-Based Leadership, 1996. In Leading Change, it's noted that management theorist James O'Toole proposes a provocative new vision of leadership in the business world-a vision of leadership rooted in moral values and a consistent display of respect for all followers. As O'Toole brilliantly demonstrates, values-based leadership is not only fair and just; it is also highly effective in today's complex organizations. When leaders truly believe that their prime goal is the welfare of their followers, they get results. The finest leaders- from political giants like Washington, Jefferson, and Lincoln to contemporary CEOs like Max De Pree and James Houghton-have always shared leadership with their followers. They create organizations that encourage change and self re-evaluation; they foster an atmosphere of open-mindedness and fresh thinking, in which assumptions can be challenged and goals reassessed. Grounded in the ideas of moral philosophy, Leading Change powerfully transcends the standard how-to management primer to define a challenging new approach to leadership. As O'Toole so persuasively argues, growth and change are possible, indeed necessary, and they will be affected by individuals who have the stature and the courage to lead morally. "Jim O'Toole has written the essential work for organizations to survive and thrive in today's changing world.

Lickona, T., Moral Development and Behavior: Theory, Research, and Social Issues, Education Resources Information Center (ERIC), 1979. This book contains selections from psychologists, social scientists, and educators on the origins and nature of moral reasoning and behavior. Part one is an introduction and is intended to help the reader organize the wealth of theory and research in the field around eight basic questions confronting a science of morality. Part two sets forth eight distinctively different theoretical views of how moral development occurs. Part three deals with research and critically examines findings in selected areas of moral functioning, pinpoints methodological problems, and suggests new methods for the study of morality. Part four looks at the moral dimensions of important social issues and attempts to derive intervention strategies from the accumulated theory and research about moral behavior. 


\subsection{The Philosophic Dimension: Theoretic Background on Moral Education}

We believe that morality should be taught through practical methods, concentrating on the discussion form dealing with a list of moral components, when dealing with others to be treated:

- Concern for people as equals

- Justice and respect for other people

- Benevolence, fraternity, and love

- Having the relevant know -how or social skills for moral thinking through respect of verbal and non verbal communication

- Relevant alertness, noticing moral situations, and thinking thoroughly about them.

Therefore the moral developments of individuals seek practical methods in ethics, accepting responsibility and authority correlation with freedom.

One should make moral thinking conceptually to judge the right or wrong answers to moral problems, and set values from a humanist or utilitarian point of view.

So moral thinking is about how people ought to think in the moral values, such as truthfulness, courage, justice, respect, equality, benevolence, and to be able to develop the ability of moral action after self - awareness, so that the moral equation will be to make a moral decision and to produce the right action. (Wilson, 1972)

We all know that the main problem in moral education today is the changing of moral standards. And one of the main principles of moral education includes greater recognition of the common humanity fostering the exercise of power of choice, greater encouragement of initiative, taking responsibility, and knowing that there is no morality without decisions.

We recognize that moral education is more needed in a rapid social change era. For example, during this century the way of life in the civilized world has altered more violently .But socialization sets a role responsibility. Since reason and habit are the paradox of moral education, one needs intellectual training, development of critical thought of choice, Socrates once explained, and as Aristotle mentioned in the book of Nicomachean ethics.

A lot of interest should be in the social humanitarian interpretation of morals where the humanitarian criteria include concepts of justice, loyalty, respect of rights, self reliance, frankness and intellectual honesty. (Niblett, 1963)

I do believe in the power of culture, and that humans are creators of cultures, and morals, so they are real agents of socialization.

One of the real problems we are facing nowadays is the culture of violence and tribalism caused by the effect of media, and social changes.

On the other hand, we need an emphasis on the culture of pluralism, trying to understand the cultural evolution of the self consciousness, and accepting that humans are valeurs. It seems that the Arab mentality is lacking a real good moral and aesthetic sensibility, so that we need to become morally more mature within this context of cultural relativism and multiculturalism. So we must remodel our morals, reinforcing more appropriate behavior focusing on virtues such as compassion, honesty, perseverance, and non-violence, responsibility, justice, courage, respect for the rule of law, respect for life, and respect for human dignity (Hutcheon, 1999).

\section{Methodology}

\subsection{Statistical Analysis and Data Interpretation}

In order to reach conclusions about moral values owned and believed in by students of Petra University, a questionnaire made up of 50 statements was developed.

\subsection{Description of Study Sample}

The questionnaire was distributed to more than 300 student, some of the questionnaires were deleted because of not being properly filled, the rest to be analyzed were (296). They were divided into (53.7) percent for males with frequency of (159), while females were (46.3) percent, and (137) frequency.

The sample included (5) Faculties as follows: Administration and Business (48.6) percent and (144) frequency (this was the highest part), then those studying Art and Humanitarian studies totaling (23.6) percent and (70) frequency, then the Faculty of IT was of (14.5) percent and (43) frequency, then the Faculty of Architecture was (8.1) percent and (24) frequency, and finally pharmacology reaches (5.1) percent and (15) frequency. 
The sample represented students of different levels, most of them were in the first year reaching (40.5) percent and (120) frequency, then those in the third year were (22.6) percent and (67) frequency, those in the second year were (20.3) percent and frequency of (60) and finally those in the fourth year were (16.6) percent with (49) frequency.

The sample was distributed to students who turned to be as Muslim with a percentage of (97.6) and frequency of (289), and Christian with (2.4) percentage, and (7) as frequency .

\subsection{Study Procedures}

The questionnaire was built to measure the moral awareness and faculty of the Jordanian youth, those under -graduates, in particular, it was transmitted and spread to different categories varying in gender, religion, and age , as university students in Jordan, such as the University of Jordan, Yarmook University, Muta university, Al -balqa University, Arab academy for financial and administrative studies, etc. The responses were analyzed to cover the whole items, that were made up of (45) points shown in conclusion and the questionnaire was made in Arabic (Appendix 1)

\subsection{Validity and Reliability Test}

Questionnaire was subjected to the validity and reliability test, in order to know the capacity of the paragraphs of the questionnaire to measure what it was developed for, The questionnaire also have been subjected to the reliability test aiming to ensure the same results if it was is re-applied to respondents again.

\subsubsection{Questionnaire Validity}

The aim of ensuring the face Validity of the measurement tool, the questionnaire was reviewed by a number of faculty members in the Jordanian universities in the same field of the study, in order to identify the suitability of the questionnaire for the goals which sought to achieve

\subsubsection{Questionnaire Reliability}

In order to ensure the Reliability of the questionnaire, the researcher used the internal consistency coefficient $(\alpha)$ according to the alpha Cronbach equation, and the value of $(\alpha) 97 \%$, which is very high when compared with the minimum acceptable $60 \%$.

\section{Results}

\subsection{Results Analysis}

When answering the question about the ethics nature in Jordanian society for student point of view, frequency and percentages was used to illustrate student point of view about ethics nature in Jordanian society, and the response was classified in many sections, and the roots of ethics education in Jordanian society (table 1) comes from the Arabic culture with percent of 41.6 percent. And nearly about 27.7 percent of the morals come from pure moral background, while 25.7 percent of the student referred the root of the moral education to the religious, whereas 5.1 percent of the student mentioned for the customs.

Table 1.

\begin{tabular}{llll}
\hline Roots of ethics education in Jordanian society & Frequency & Percent \\
\hline Valid & Religious & 76 & 25.7 \\
& Customs & 15 & 5.1 \\
& Arabic culture & 123 & 41.6 \\
& Pure ethics & 82 & 27.7 \\
& Total & 296 & 100.0 \\
moral crisis in the Jordanians society & & \\
Valid & Agree & 208 & 70.3 \\
& Disagree & 88 & 29.7 \\
\multirow{5}{*}{ Valid } & Total & 296 & 100.0 \\
& Human & 6 & 2.0 \\
& Religious & 179 & 60.5 \\
& Jordanian and locally & 33 & 11.1 \\
& according to criteria of your own & 78 & 26.4 \\
& Total & 296 & 100.0 \\
\hline
\end{tabular}


While the increasingly visible moral crisis in our society because of the weakness of Jordan's sense of moral, Table 1 about 70.3 percent of the sample believe that there is a moral crisis in the Jordanians society. While 29.7 percent of the responders believe that there are no moral crises in society.

From Table 1 it's also noticeable that 60.5 percent of the sample influence by religious values, while 26.4 percent of the responders influence by own criteria. Nearly 11 percent of the sample responders used his/her local Jordanian judgment. Very few percent of the sample 2 percent used a human reference to judge the most appropriate action.

Table 2.

\begin{tabular}{llll}
\hline & & Frequency & Percent \\
\hline Agree with & yes & 178 & 60.1 \\
morality & no & 118 & 39.9 \\
& Total & 296 & 100.0 \\
Important & Spirituality & 85 & 28.7 \\
two values & Biological values such as caring for the body and the right of & 23 & 7.8 \\
& life & 23.6 \\
& Values of the secretariat for the behavioral & 70 & 19.9 \\
& The emotional values & 59 & 14.5 \\
& The social values & 5.1 & .3 \\
& Mental values & 43 & 100.0 \\
& Missing & 15 & 9.8 \\
& Total & 1 & 9.5 \\
& Parental age and their culture & 296 & 74.0
\end{tabular}

If the pragmatic ethics mean myself and to choose what suits me, the agrees and disagrees (table 2) show that above $60.1 \%$ of the sample choose what suit them and contribute to gain benefits, while $39.9 \%$ of the sample they didn't choose what suit them and contribute to gain benefits. While the most important two values (table 2) were $28.7 \%$ for spiritual , $23.6 \%$ for the emotional value, $19.9 \%, 14.5 \%$ for the social value, $7.8 \%$ for Biological values such as caring for the body and the right of life , and $5.1 \%$ for mental values.

Table 2 above shows that $74 \%$ of the responder believes that, the economic situation of the family consider the most important factor in the moral education, while few percent pd the responders $9.8 \%, 9.5 \%$, and $6.8 \%$ believed with follow factors respectively parental age and their culture, good relationship between a parent, role of the environment surrounding the individual

Table 3 shows that $26 \%$ of the responders believed that the most important role in education is due to social institute clubs, $24.3 \%$ family, $23 \%$ for media, $7.1 \%$ for schools and $2 \%$ for the university.

Table 3.

\begin{tabular}{llll}
\hline I think the most important role in education is due to: & Frequency & Percent \\
\hline Valid & The family & 72 & 24.3 \\
& School & 21 & 7.1 \\
Houses of worship & 52 & 17.6 \\
Social institutions and clubs & 77 & 26.0 \\
Media & 68 & 23.0 \\
Universities & 6 & 2.0 \\
Total & 296 & 100.0 \\
\hline
\end{tabular}




\begin{tabular}{llll}
\hline \multicolumn{2}{l}{ The most important role of universities in moral education } & & \\
Valid & The development of the spirit of good & 6 & 2.0 \\
& Development of a spirit of brotherhood & 12 & 4.1 \\
Develop a spirit of subordination of the moral system & 170 & 57.4 \\
The development of conscience and personal moral & 104 & 35.1 \\
Missing & 4 & 1.4 \\
Total & 296 & 100.0 \\
\hline
\end{tabular}

Table 3 above, also show that $57.4 \%$ of the responders believed that the most important role in education is due to develop a spirit of subordination of the moral system, and $35.1 \%$ of the responder believed that the development of conscience and personal moral, $4.1 \%$ believed that the Development of a spirit of brotherhood, and $2 \%$ believed with the development of the spirit of good.

In Table 4, and when answering the question about the nature of ethical value among students, the analytical results show that $35.1 \%$ of the responders believed that the important characteristic of the moral character of the manifestations in resist the temptation, $30.4 \%$ honesty, $25.3 \%$ sense of guilt when the error, and $9.1 \%$ sacrifice and altruism.

Besides that, Table 4 when discussing the missing standard of honesty in dealing, the rustles show that $56.4 \%$ of the responders agree with missing students to the standard of honesty in dealing, $13.5 \%$ agree to a certain extent, and $28 \%$ disagree.

while the missing students to the standard time commitment shows in Table 4 that $61.1 \%$ of the responders strongly agree, and agree with missing students to the standard time commitment, $15.2 \%$ agree to a certain extent, and $24.7 \%$ of the them disagree.

Table 4.

\begin{tabular}{llll}
\hline nature of ethical value among students & Frequency & Percent \\
\hline Valid & Sense of guilt when the error & 75 & 25.3 \\
& A sacrifice and altruism & 27 & 9.1 \\
& Honesty & 90 & 30.4 \\
& Resist the temptation & 104 & 35.1 \\
& Total & 296 & 100.0 \\
Missing standards of honesty in dealing & & \\
Valid & Strongly agree & 6 & 2.0 \\
& Agree & 167 & 56.4 \\
& To certain extent & 40 & 13.5 \\
& Disagree & 83 & 28.0 \\
Missing students to the standard time commitment & Sotal & 296 & 100.0 \\
Valid & Agrongly agree & & \\
& To certain extent & 71 & 24.0 \\
& Disagree & 107 & 36.1 \\
& Total & 45 & 15.2 \\
& & 73 & 24.7 \\
\hline
\end{tabular}

\section{Discussion}

Taking into consideration statistical analysis, the following are the main results driven:

There is no real accurate understanding of moral terms in the minds of students, so that they mix terms such as moral awareness, moral sensation, conscience, super-ego, the difference between good and bad, right and justice, and even the moral dilemma and crisis. Students also have a weak awareness of what is a moral choice, and 
therefore there were extremes in moral thinking from students' points of view. Moral thinking to them was not based on analyzing the moral dilemma.

Most of the students referred to religious origin of moral religion, with a clear effect of some Arab traditions, which sometimes has nothing to do with morality. They believed that morality has a nature of absolutism that doesn't change with time and place, and that has to do with the effect of religion, while they didn't believe in what is called relativism in morality and accepting the idea of change according to time and place. Most of them did not differentiate between justice and equality, which entails a problem in its practice.

Most of students believed that morals development are more affected by the family, then information organizations, rather than the very slight effect of higher education organizations. Most of them believed that the essence of virtues is happiness. They also thought that religion comes before morality, and morality comes before law, and this affects their priorities in moral choices when they judge moral dilemma.

Most of them believed in moderateness in virtues as explained in Islam, where such virtues come between two extremes: courage, modesty, generosity friendship, honesty, forgiveness, and acceptance. They believed that globalization, modernity, information, and technology have effects by necessity on morality.

They believed that moral education acceptance increases according to educational level.

It is concluded by them that the worst moral qualities in the Arab world are: Corruption, untruthfulness, and weak moral wills with no moral awareness. They believe in morality from a perfectionist non-practical point of view. They refused the idea that man is the creator of morality, hence it's rather God.

They also believe in the role that universities have to take upon their responsibilities, saying that it wasn't enough efforts. And most of them believe that freedom has nothing to do with morality, so that there is no moral choice, it is rather a must and it is absolute. Their morality is more affected by their feelings, and sensations, therefore the Arabs are more emotional. They believe that more moral crises appear in the Jordanian society because of weak moral sensation weakness generally in youth, and that the environment, and some bad habits are mostly affecting morality awareness.

Students usually choose on a religious basis rather than a human moral one or even a Jordanian basis.

They don't believe in flexibility in ethics, saying that it has to be strict. Most of the under-graduate youth believed in pragmatic morality, although of the fact it's contradictory to the Islamic principles of morality. Most of them believed that the worst immoral qualities are terrorism, then ignorance and untruthfulness.

And when thinking about types of virtues, most of them chose spiritual and biological virtues, then emotional, rather than practical, social, and mental virtues. They believed there should be a neutral unbiased measure for morality, and not a double standard one as the pragmatic morality may accept. And in that there is a lot of contradiction.

It seems there was no real understanding of the necessary relation between responsibility, commitment, and morality.

They don't necessarily see the relation between freedom and morality. And they believe that mental ability is a prerequisite of reward and punishment for moral actions.

Students believed that the most appropriate way to raise moral sensation and awareness is setting a good model and stories on that, in addition to the method of the rewarding system for good and bad, and it is not the practice of trying the good to see the benefits nor dialogue before moral choice as should be in the democratic method.

They mostly agreed that there is deterioration in moral practices in Arab societies nowadays. They believed that the age of parents and their education, their mutual level of relation and maturity have a great impact on the moral conduct of their children, rather than the effect of others, such as poverty or the economic situation of the family for example.

Most of students were indirectly expressing their rejection of women's participation in work, saying that it may have a negative effect on children by neglecting them. They believed that the role of universities should be in developing the student's moral personality which is not their real concern, while there should be more concern in raising their moral order compliance and obedience, and more fraternal hood understanding is needed.

They mainly believe in altruism and the sense of sacrifice as their prior values, rather than the belief in loyalty and faithfulness, as their priorities. They believe that they mainly lack a really good sense of truthfulness, time commitment, and moral commitment, they rather commit to tradition than moral standards. 
Most of Jordanian students set their role models as prophet Mohammad or Islamic characters, such as Abu-baker, or Jordanian figures as King Abdullah II, or their family members as their fathers, mothers, brothers and sisters, and one of the most amazing answers was choosing God as a role model, so that they believe only in the supernatural moral models of God, rather than human beings.

Man is created as a moral being with his good will believing in main virtues: right, good, and beauty. So that man is the only creature who believes, and the only one having morals and free will, and therefore, the only one as creative through combining the three virtues.

As we know deeply that morals is about what should be, with an act of free will and moral choice seeking perfection in life.

But as we recognize that human nature is relative and not absolute, virtues are moderate, where there is no extreme in morality. This is clearly shown through results of questionnaires analyzed within the Arab - Islamic framework and term of reference.

Examples on that seeing courage, modesty, honesty, faithfulness, generosity, altruism, responsibility, forgiveness, in such a context.

The following description is clearly shown in an Arab - Islamic morality where principles of morality are based on good virtues, as honored and useful one.

Therefore, we understand that justice is the root of virtues illustrating wisdom, courage, modesty, honesty and generosity.

And refining the soul comes through requesting good and happiness, which is in Islam, the same concept discussed by Plato and Pythagoros in the other well -known Greek philosophy.

For example, Ibn- Miskaweih, a Muslim philosopher combines both spiritual and material virtues, while the first is clearly manifested in angels; the second is embodied in beings.

We all recognize that reaching a moderate state of morals is a hard thing to achieve, but in Islam, it is moderateness in morality that is requested, and this is quite different from the concept of relativism in morality that is presented in the western culture as compared to the eastern Arab one.

Man is social and civil by nature, so that morality is only through moral actions, so it is in both by deeds and intents that makes it good morally in the Arab Islamic culture, and this is totally against the Machiavelli's belief.

In Islam, man was born by nature, as good, and this is fair enough, as opposed to what Galinus for example thinks, as some are born good and some are bad, and as it is also mentioned by the father of ethics in Greek culture, Aristotle in his book of ethics, that the bad become good through moral education, and that is different for people according to their classes, and that man's perfection is through both powers: the knowledgeable, and the forcible.

Our eastern moral culture faces real moral dilemmas, and that is because we live in an era of masses, alienation, bad education system, depression in human moral nature, and weak moral will, awareness, and personalities. Some reasons for that may be the continuous compulsory quest for hedonistic pleasures, extreme request for protectiveness, depression, losing innate personal moral values, and the loss of ethical common sense agreement.

Some of the moral defaults clear in nowadays ethics are: lack of self -control for the good, lack of responsibility, false friendship, mistreatment of both minds and feelings, unfaithfulness, misuse of power, jealousy, selfishness, corruption, blackmailing, self-deception, lack of personal merits, ignorance of the difference between good and bad, manipulation, malice, and breaking promises.

Nowadays, Arab people have come to a conclusion that they have certain moral principles to follow on both the personal and collective moral levels: so that they have to reprioritize their personal virtual goals, according to the good and the useful in adhering to moral commitments to loyalty, integrity, self-control, free moral choice, moral personality enrichment, adjusting to nature and acting in compliance with the egalitarian justice principles of morality.

In other words, we as Arabs need to reconsider and study our actual historic moral philosophic context trying to seek perfection towards a more normative standard of morality, bearing in mind that our moral structure should maintain both: the cognitive moral basis and the actual moral deeds, based on theoretical and actual faith in the states of consciousness, moral rights and free moral will, according to the positivist, empirical, development of morals in the Arab Muslim state of mind. 
And this is exactly the same as the philosopher Bertrand Russel (the logical positivist follower), who believed that the philosophic moral frame is mainly made up of feelings and not of empirical recognitions, so that morality is in the essence of the self.

Man in Islam, therefore, isn't the creator of morality, but God is the one who created the super -ethical ego of man as a free will. So they believe that moral principles and regulations are supernatural and sent by God to prophets or messengers, like Jesus, Mohammad, Buddha, bearing in mind that codes of ethics were imposed for the sake of social needs for moral order.

Morals in Islam are not only theoretic as to Socrates in his theory identifying virtue with knowledge, but it is practical in (Shariaa), and moral wisdom, is therefore in maintaining both. So if we compare the Islamic morality to other philosophies, we find it social, while it is based on hedonism to Epicurus, happiness to Aristotle, utility to Bentham and Mill, duty and free good will to Kant.

The Arab morality focuses on man as having an evolutional entity for moral experiences and with an intelligible character. And since the values dilemma is clear when facing the state of inner vacuity, we can see that the moral experience of the Arab man lies in being a good tester of the realm of values having the moral faculty. This is why we really need a revolution in ethical theories and to rebuild our emotional moral faculties.

We can therefore recognize more than one dimension in moral conducts in the Arab frame, the dimension of content, where we can see theoretical values, with economical one, aesthetic social, political, religious, together with a dimension of intent, as we know that deeds are by intents too in this culture, where moral sensation is not enough, there should be also moral responsibility and obligation. And this is why in relativism of morality as contrasted with absolutism there should be reconsideration of the curriculum of morals, personal moral identity, identification of moral models and paradigms with consciousness to raise achievement and success in Arab behavior

\section{Acknowledgements}

Ethics is about the moral choices people make and the values by which they live.

We are living in a state of moral chaos. Once Socrates said that real knowledge comes from discussion and argument, and that the purpose of our life is to find happiness in the form of wealth, fame, and wisdom. And I believe that we can find real happiness in achieving a spiritual perfection of the real self or soul. So morality is a set of rules and a social contract, it is a part of the structure of the universe, which is according to the teleological view, human beings are fulfilled and happy when they are functioning well.

Whereas in our Arab Islam context, there is no belief in what is called the Mechiavellian practical morality, where we can find two sets of moral standards, one for the government and one upon the social contract.

The real question is why has ethics become a mess?

Maybe because we are facing new challenges, and different moral priorities, so whereas we see in the Feminist ethics the model of (S.H.E.): which is sane, humane, ecological society that culminates into peace. On the other hand, we can see the holistic ethics based on the usefulness of values no matter how it affects the diversity of things.

In that case, we find ethics as etiquette and politics, so that politics can be a necessary expression of ethics, as often the only way to achieve an individual ethical goal is through group endeavor, i.e. politics.

Our real problem lies in not really exercising moral choices, which is the real choice between two horns (as was meant in Greek) the choice between good and bad. So in the end ethics study how to organize the world with harmony.

Yes, Islam is a global faith which means literally submission to God, and Islam ethics are a comprehensive approach to living, covering all aspects of life, social and individual, material and spiritual, religious and political.

This is why we need to work on new calculations of rights, laws, happiness, and morals, and to reject the dominant value system, and try to develop.

Finally, I assume that the previous discussion was rather an analytical moral pedagogy, mutual respect, moral consciousness, how to build moral competence, seeking a real democratic education in universities through achieving a moral atmosphere, whereas we need a gradual change in moral reasoning, moral commitment and moral action. 


\section{References}

Abdo, M. (1999). Moral Philosophy. Second edition, Cairo, Egypt for publication (Arabic source).

Aljaber, M. (1994). The Fundamentals in Ethics, first edition. Damascus, Dar Almarefa (Arabic resource).

Bebeau, M. (1999). Beyond the Promise: A Perspective on Research in Moral Education. Sage journals.

Ben Musqaweih, A. (1961). Tahtheeb Alakhlaq. Beirut, Lebanon press, (Arabic resource).

Cohen, R. (2003). The Good, the Bad and the Difference: How to Tell the Right from the Wrong in Everyday Situation, Newyork, West.

Dave R., \& Chris G. (2000). Introducing Ethics. Australia, Richard Appignaness.

Dennis L. Thompson. (1993). Moral Values and Higher Education. USA, Brigham Young University.

Hutcheon, P. (1999). Building Character and Culture. United States of America, Praeger publishers Westport.

Ibrahim, Z. (1992). The Moral Dilemma. Egypt, Dar Alshorooq (Arabic Resource).

J O'Toole. (1996). Leading change: The argument for values-based leadership. UK, Ballantine Books.

John W. (1972). Practical Methods of Moral Education. London, Heinemam educational books.

John, P. (2002). Morals for the $21^{\text {st }}$ Century. first edition, Damascus, translated by Ahmad Ramo, Almatabe.

Joseph, J. (1979). Moral Judgment as a Predictor of Clinical Performance. ERIC Journal, 3, 199.

Leming, J. (2006). Curricular Effectiveness in Moral/Values Education: A Review of Research. Journal of Moral Education, 10(3), 17.

Lickona, T. (1979). Moral Development and Behavior: Theory, Research, and Social Issues. Education Resources Information Center (ERIC), 5, 23.

Martin C. (2003). 101 Ethical Dilemmas. London, Routleledge.

Marvin W. (1985). Moral Education: Theory and Application. London, edited by Fritz Oser, Lawrence Associate

Mel T. (2000). Teach Yourself Ethics. London, Hodder Euston Road.

Nasser, I. (2006). Moral Education, first edition. Amman, Dar Wael (Arabic resource).

Niblet, W. (1963). Moral Education in a Changing Society. London, edited by Faber limited, Scots.

\section{Appendix}

1. Does their moral education refer to bases of religion, habits and tradition, Arab sources, totally moral basis?

2. Are morals in nature relative varying in time and space, or absolute, and don't change whatsoever?

3. Do morals develop by: nature, family, higher education organizations, or information organizations?

4. The bases of virtues are: welfare hedonism, or happiness?

5. Do you believe in moderateness and relativism in morality?

6. Do you agree that modernity, globalization, information and technology affect morality by necessity?

7. Morals are good virtues known and utile?

8. Do you agree that the bases of virtues are justice, wisdom, courage, generosity, and purity?

9. Do you agree that people are in scales in accepting moral education depending on their educational status development?

10. Moral awareness basis is:

a- consciousness

b- trial

c- education and learning

11. I believe in morals from a perspective of:

a- perfectionist

b- practical

c- normative 
12. Do you believe that man is the creator of morality?

13. Do you believe in the role of universities in moral education?

14. Do you believe that free will is the base of morality?

15. Do you believe that morals are based on three virtues, arranged according to priority among (right, welfare, and beauty)?

16. Do you believe that emotions and sensation mostly affect morals?

17. Do you believe that moral personality and moral consciousness are main reasons for moral conduct?

18. Do you believe that there is no moral conduct without moral choices?

19. Do you think that more moral crises appear in the Jordanian society due to weakness of moral sensation?

20. Do you believe that the most effective reasons in morality are :

a- heredity

b- habit

c- environment

21. What is it that mostly controls your moral development?

a- nature

b- habit

c- conscience and super-ego

22. Which is more important to you when choosing, to choose on a basis of :

a- morality and humanity

b- religion

c- Jordanian and regional

d- your own set rules

23. What is of a major effect on your moral development? And what is it that shocks you morally?

24. Do you agree with moral flexibility?

25. You interpret morals according to :

a- hedonism and happiness

b- utility

c- duty

26. Do you agree that the practical morals are absolute in virtues as the theoretical ones?

27. Do you agree that the pragmatic morality means choosing what is the best for me and more utile from moral choices?

28. The worst qualities to you are:

a- Ignorance

b- Terrorism

c- Extremeness

d- Lying

29. Which is the most important virtue to you:

a- Spiritual virtues such as faith in god

b- Biological virtues such as the right to live.

c- Conduct virtues such as faithfulness

d- Emotional virtues such as love

e- Social virtues such as brotherhood

f- Mental virtues such as creative thinking 
30. Do you believe in the existence of a neutral standard for morals?

31. Is there a necessary relation among responsibility, commitment and morality?

32. Do you agree that free will is the essence of morality?

33. Do you agree that mental capacity is the essence of reward or punishment for moral practices?

34. Do you believe that our Jordanian Arab society is losing moral development?

35. What is the best way to develop and educate morally?

a- Good model

b- Teach

c- Practice

d- Reward and punishment

e- Conscience

f- Good stories

36. I believe that the most critical role of moral education goes to:

a- Family

b- School

c- Social organizations

d- Prayer places

e- Universities

f- Information

37. The most influential on moral education for people is:

a- Parent's age and education

b- Good relationship with parents

c- Family economic situation

d- Environmental surroundings

38. Do you think women's work badly affect moral education for children?

39. What is the role of universities on moral education?

a- Develop good will

b- Develop fraternity

c- Develop submission to moral system

d- Develop conscience

40. What is the most that describes your moral personality?

a- Feeling guilty when wrong

b- Altruism and sacrifice

c- Truth and faithfulness

d- Temptation control

41. What is our main moral crisis in our society?

42. Do university students use good language when communicating?

43. How truthful and honest in conduct?

44. What about time commitment?

45. Are they conservative in clothing?

46. Who is your moral role model? 